\title{
DUPLICATION OF SMALL GUT PRESENTING AS OBSTRUCTION IN AN ADULT PATIENT: A RARE CLINICAL PRESENTATION
}

\author{
Anurag Bijalwan ${ }^{1}$, J.P. Sharma², Subhash Sharma ${ }^{3}$
}

\section{HOW TO CITE THIS ARTICLE:}

Anurag Bijalwan, J.P. Sharma, Subhash Sharma. "Duplication of Small Gut Presenting as Obstruction in an Adult Patient: A Rare Clinical Presentation". Journal of Evolution of Medical and Dental Sciences 2014; Vol. 3, Issue 05, February 03; Page: 1218-1220, DOI: 10.14260/jemds/2014/1971

ABSTRACT: Duplication of gut presenting as perforation, peritonitis in an adult is a very rare clinical presentation. Here we report a case of an adult female patient in generalized peritonitis was caused by perforation of tubular communicating, duplicated, Ileal loop which rotated at its attachment with main ileum. This condition was managed by performing laparotomy, excision of the duplicated gut segment followed by end to end ileoileal anastomosis.

KEYWORDS: Duplication of small intestine, Obstruction and perforation, Resection and anastomosis.

CASE REPORT: A 32 yrs. old female presented in surgical OPD with the history of generalized abdominal pain, gradual distension and vomiting off and on for the last 3-4 days. She had been suffering from episodes of these symptoms for past couple of months, suggestive of sub-acute intestinal obstruction. However for last few days, these symptoms were aggravated.

Patient had been empirically put on ATT by clinicians whom she had been consulting before coming to our hospital. Patient had undergone laparotomy about 8 years ago for perforated appendix. Patient appeared quite ill, dehydrated with tachycardia tachypnea and mild fever.

Physical examination, revealed distended abdomen with tenderness and guarding all over. Rebound tenderness was also present. No hepatosplenomegaly was detected. P/V and P/R examination were within normal limits. A right paramedian scar from previous surgery was present.

Hematological profile revealed normal study. X-ray abdomen erect view showed multiple Air fluid levels. USG study of abdomen showed mesenteric thickening with mild fluid and dilated bowel loops. She was taken up for Exploratory Laparotomy after correcting her dehydration.

Abdomen was opened through mid-line incision which revealed dilated small bowel loops with free fluid. Exploration revealed about one feet long tubular, dilated and duplicated gut which had rotated upon its own axis where it was joining with the main gut, communicating at both proximal and distal ends, causing obstruction and perforation. [Fig. 1, Fig. 2]. The segment had no independent mesentery. It derived it's vascularity from the main ileal wall segment with which it was communicating (as shown by a hand inserted in the intervening empty space between the two segments in the Fig. 2). This segment was about $2.5 \mathrm{ft}$. away proximal to ileocecal junction.

This duplicated gut segment was resected and an end to end ileoileal anastomosis was done. No evidence of abdominal Koch's was detected.

Her post-operative period remained uneventful and she was discharged fifteen days after surgery.

HPE Report: Revealed duplication of small gut with all three layers. No evidence of heterotopia, dysplasia or tuberculosis was found. 
DISCUSSION: Alimentary tract duplications are rare congenital malformation that can occur at any site in the digestive tract. Duplication may be as a cyst or rarely as a tubular structure on the mesenteric aspect sharing a common vascular and muscular wall with the main segment but separated by mucosal lining1.

Ileum is most commonly involved (63\%) followed by stomach and duodenum ${ }^{2}$. Most patients with duplication present with a palpable abdominal lump, ${ }^{3}$ bowel obstruction, intussusceptions and/or hemorrhage due to heterotrophic gastric mucosa in the duplicated segment ${ }^{4}$ but peritonitis caused by perforation of the duplication is rarely seen ${ }^{5}$.

Many theories have been put forward in an attempt to explain these duplications. Lewis and Thyng frequently found diverticula in the fetal alimentary tracts of pigs, rabbits, cats, sheep and man ${ }^{6}$. These knob-like outpockets of the intestinal wall normally regressed, but the pinching off of one of these structures, separating it from the normal intestinal wall, was thought to be the mode of formation of these abnormalities.

Bremmer $^{7}$ attributed duplication to a failure of cystic spaces which convert a solid stage of the intestinal canal into a tube, to join up with the main lumen. Other possible explanation is that duplication represent a localized form of twining. Foetal stress and anoxia caused by vascular in sufficiency during intrauterine life have also been implicated as a cause of duplication of gut ${ }^{9}$. This case is unusual for its presentation in adult age group, tubular structure with no heterotrophic mucosa and presenting as perforation peritonitis.

\section{REFERENCES:}

1. Macpherson R.L. Gastrointestinal duplication: clinical, pathologic, etiologic and radiological consideration. Radio graphics. 1993; 13:1063-1080.

2. Maingot R, Schwartz S.J, Ellis H and Husser W.C. Maingot's abdominal operations (9th edn). Norwalk, Conn. Appleton and Lange;1989.p.816.

3. Rowe M.I, O'Neill J.A Jr, J.L. Grosfeld. Enteric duplication in infancy and childhood. Annal of Surg. 1970; $172: 83$.

4. Wooler G.H. Duplications of the alimentary tract. Br J Surg. 1950 Jan; 37(147):356-8.

5. Sakamoto, Kazuhiro, Hasegawa, Seiji, Yamazaki, Yasunobu et al. Ileal Duplication Presenting as Perforation: Report of a Case. Surgery Today. 2000; 30: 445-447.

6. Ladd W.E, Gross R.E. Surgical treatment of duplications of the alimentary tract enterogenous cysts, enteric cysts or ileum duplex. Surg Gynecol Obstet. 1940; 70:295-307.

7. Bremer J. L. Diverticula and duplications of the intestinal tract. Arch. Path.1944; 32:132.

8. Needham J. Biochemistry and morphogenesis. New York: University Press, Cambridge. Macmillan Co; 1942. p. 785.

9. Favara B.E, Franciosi R.A, Akers D.R. Enteric duplications: thirty seven cases. A vascular theory of pathogenesis. Am J. Dis Child. 1971; 122:501-506. 


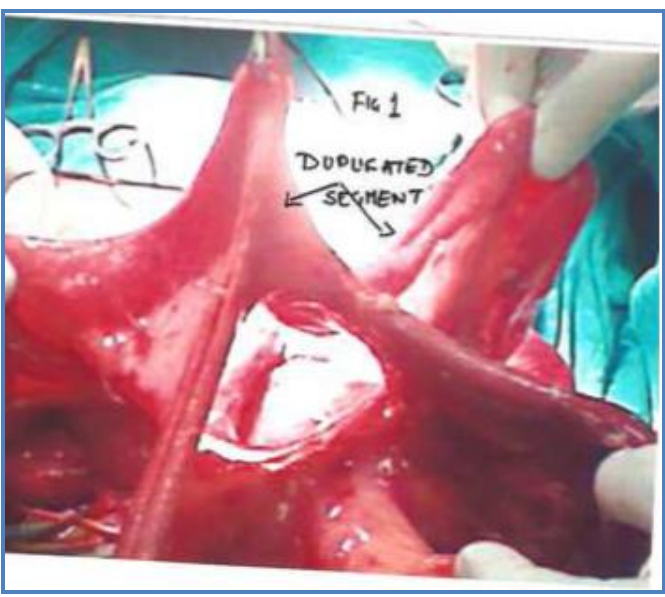

\section{FIG. 1: Duplicated segment (shown by arrows)} joining proximal and distal small intestine.

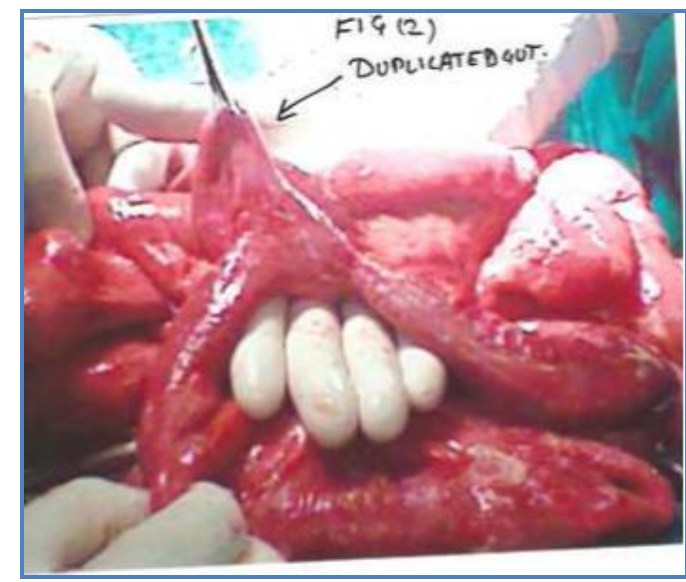

FIG. 2: Inserted hand showing attachment of proximal and distal end.

\section{AUTHORS:}

1. Anurag Bijalwan

2. J.P. Sharma

3. Subhash Sharma

\section{PARTICULARS OF CONTRIBUTORS:}

1. Assistant Professor, Department of Surgery, SGRRIM \& HS, Dehradun.

2. Associate Professor, Department of Surgery, SGRRIM \& HS, Dehradun.

3. Assistant Professor, Department of Surgery, SGRRIM \& HS, Dehradun.

\section{NAME ADDRESS EMAIL ID OF THE} CORRESPONDING AUTHOR:

Dr. Anurag Bijalwan,

1077 - Indranagar,

Dehradun, Uttrakhand.

E-mail: abijalwan@yahoo.co.in

Date of Submission: 09/01/2014.

Date of Peer Review: 11/01/2014.

Date of Acceptance: 20/01/2014.

Date of Publishing: 29/01/2014. 